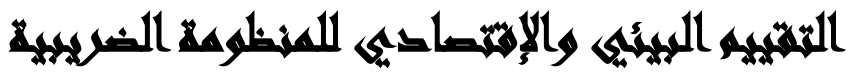

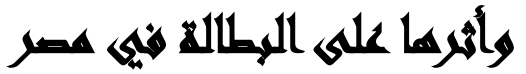

$[r \wedge]$

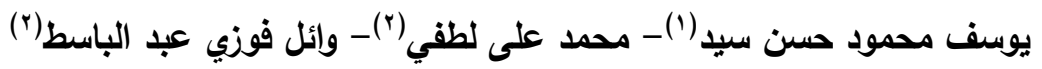

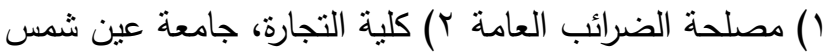

\section{المستخله}

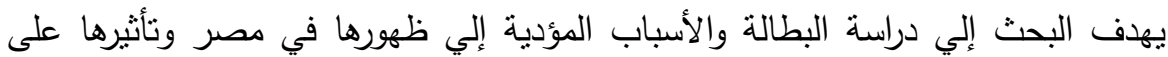

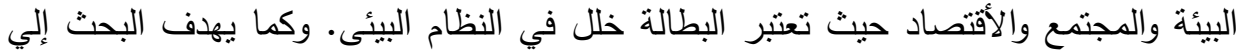

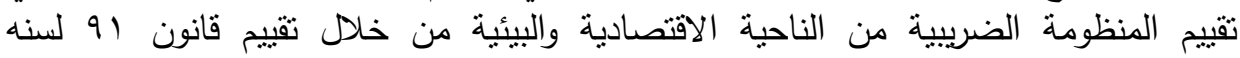

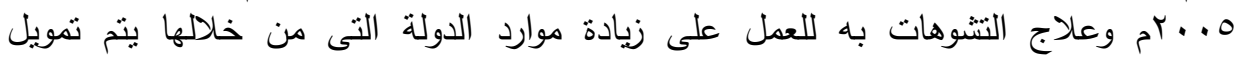

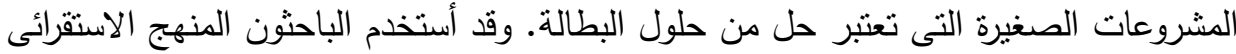

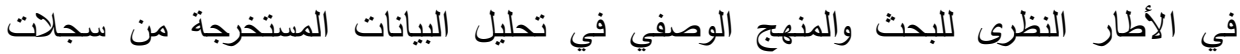

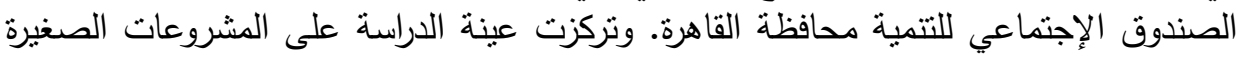

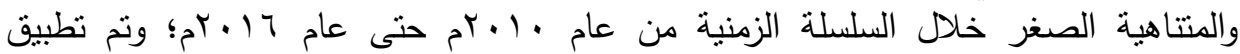

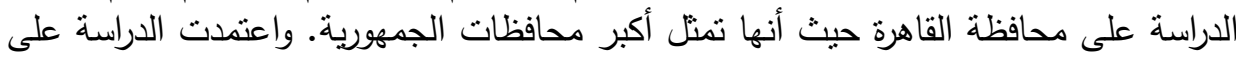

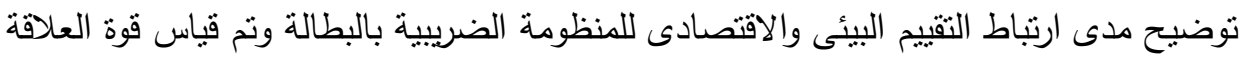

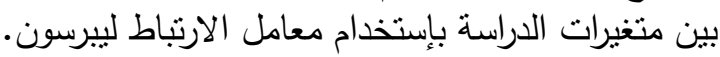

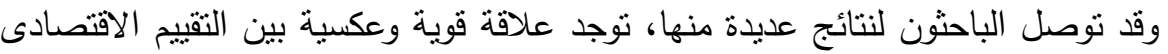

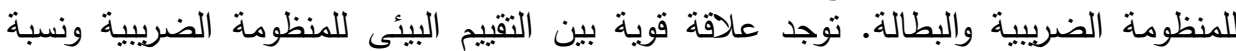

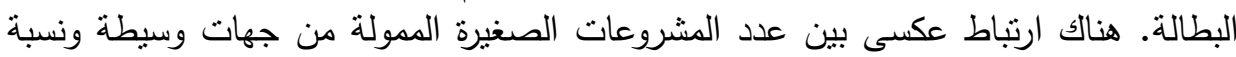

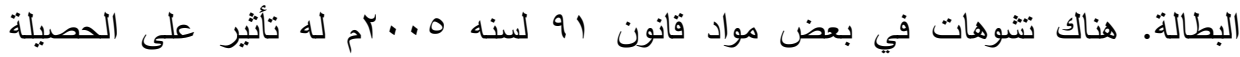

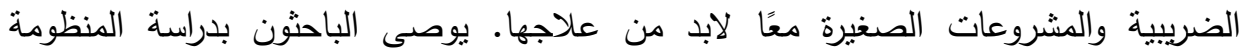

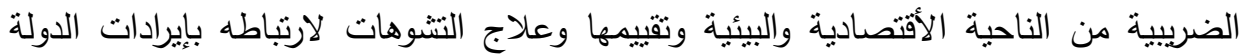

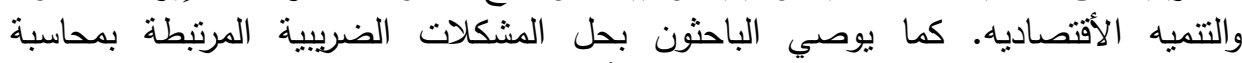

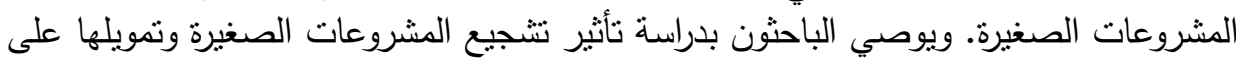
البطالة كأحد حلول تقييم المنظومة الضريبية في مصر . 


\section{المهيكية}

لقد كانت الضرائب وما زالت ثُرض بموجب القانون لتحقيق مجموعه من الوظائف

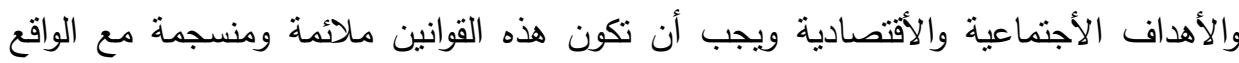
لتوفير مناخ ملائم للاستثمارات ودعم التتمية الأقتصادية وتتظيم العلاقات الضريبية وتحقيق هليق العدالة الأجتماعية وعلى ذلك يلزم تقييم المنظومة الضريبية أول بأول وعلاج التشوهات لتأثيره على ايرادات الدولة.

ومما لاثك فيه أن النظام الأقتصادي السائد في الدولة يؤثز وينأثز بالنظام الضريبى ويكون منسق مع النظام الضريبى الذي يخدم التتمية الأقتصادية (سعيد عبد المنعم، و IVV

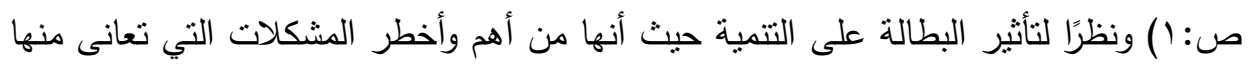
معظم النظم الأقتصادية في العالم والتي تؤدى إلي نتائج سلبية في المجال النية الأقتصادى

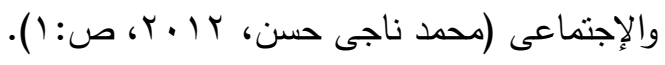
وتعد مشكلة البطالة أحد أهم الثواغل الأساسية على أجندة العمل الوطني والسياسي ليس ذلك فى مصر فقط بل في الدول الرأسمالية الصناعية المتقدمة وكذلك الدول الرأسمالية المتخلفة

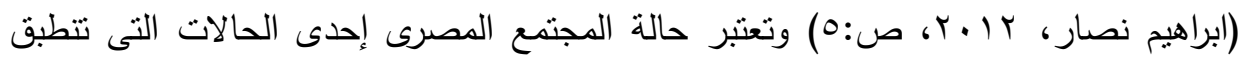

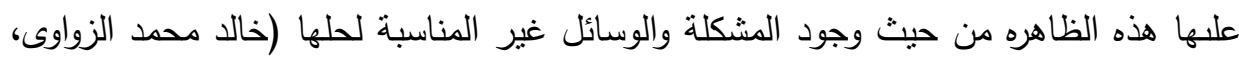

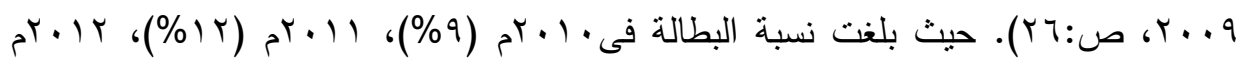

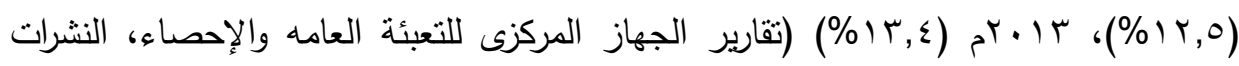
السنوية) ونظرًا لتأثير هذه الزيادة على التتمية الأقتصادية والبيئة مما جعل الأهتمام بتحليل

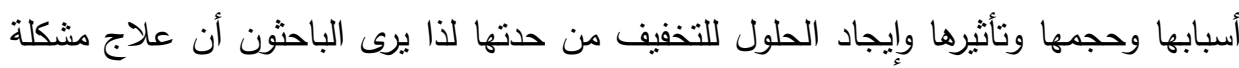
البطالة من خلال الوفورات والعائدات الضريبية الناتجة من تقييم المنظومة الضريبية من وجهنى

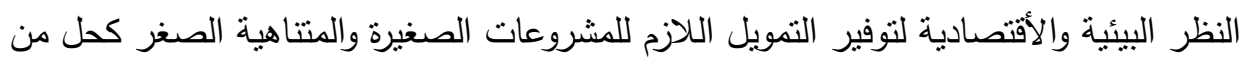




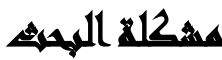

تتلخص مشكلة البحث بإزدياد أعداد البطالة في مصر، حيث تعتبر البطالة من أخطر

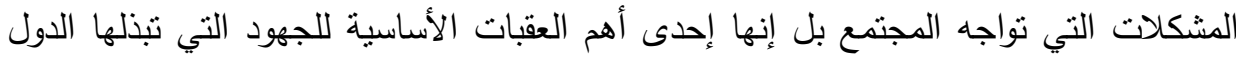

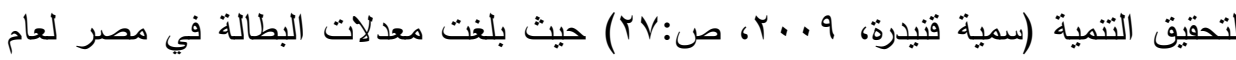

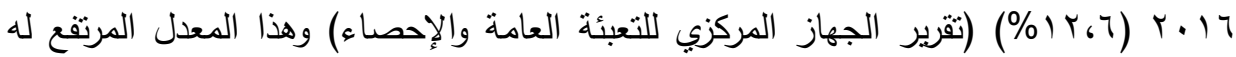
تأثير على التتمية الإقتصادية ولا يوجد حلول تحد أو تخفف من هذه الزيادات لعدم توافر التمويل اللازم بالموازنة العامة للدولة لتتغيل العاطلين، كما تتعلق مشكلة البحث بالتقييم البيائي

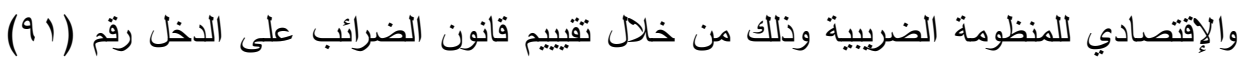
لسنة ه. . ب الذي حاول فيه المشرع معالجة بعض المشكلات منها زيادة حجم المتأخرات

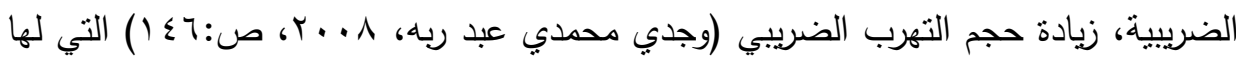
تأثثر على إيرادات الدولة ومدي تأثثر وعلاقة هذا التقييم على المشروعات الصغيرة والبطالة كحل من حلول مشكلة البطالة في مصر .

\section{اسمكلم اللهبه}

1. ما مدى وجود علاقة بين التقييم البيئى للمنظومة الضريبية والبطالة في مصر؟

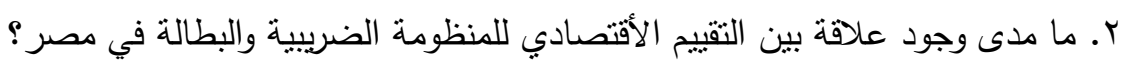
r. ما مدى وجود علاقة أو تأثنير للبطالة على المنظومة الضريبية في مصر؟

\section{الهمهية الهبهم}

نظرًا لازدياد أعداد البطالة في مصر حيث بلغت معدلات البطالة عام • • • بم (9\%)

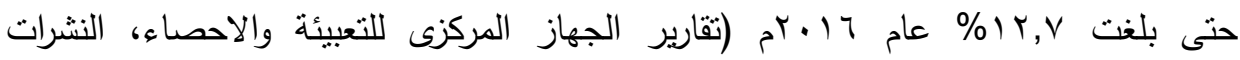
السنوية) وتأثير هذه الزياده على التتمية الأقتصادية والمجتمع يرى الباحثون الأهمية مكان دراسة

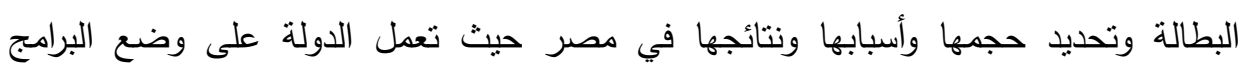

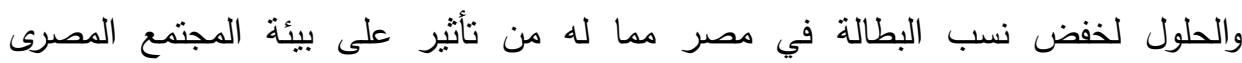

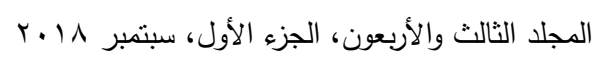


والأقتصاد، كما أن للتقييم الأقتصادي والبيئى للمنظومة الضريبية تأثنر على البطالة بصفة

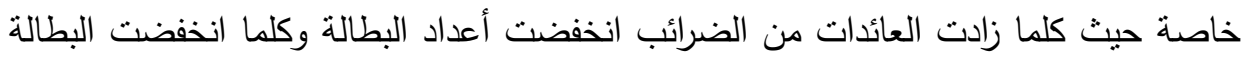
زادت العائدات من ضرائب الدخل (المرتبات وما في حكمها) كل ذللك من خلال دراسة تأثير

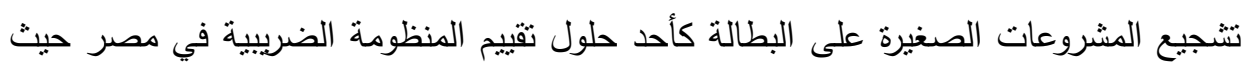
أظهرت الدراسات أهمية المشروعات كأحد حلول البطالة (سميه فتيدره، 9 . . ؟ ).

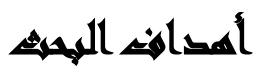

1- دراسة البطالة ومفهومها والأسباب المؤدية إلى ظهورها في مصر وتأثيرها على التتمية الاقتصادية والاستقرار الاقتصادي وعلى البيئة.

r-دراسة المنظومة الضريبية في مصر من الناحية الاقتصادية والبيئية وتقييمها وعلاج التشوهات في كل منها لما لارتباطه بإيرادات الدولة، حيث أنه كلما قلت التشوهات في ولنه

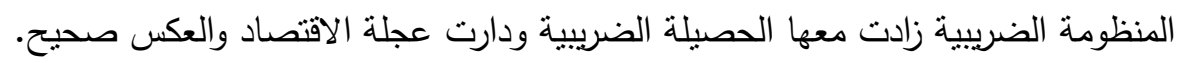
r-التعرف على العلاقة بين التقييم البيئي والاقتصادي للمنظومة الضريبية والبطالة في مصر؟ وهل هناك علاقة بين تشجيع المشروعات الصغيرة وتمويلها وبين البطالة في مصر؟

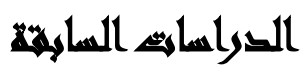

دراسة محمد عصمت درويش غانم(1999 19): تهدف الدراسة إلى معرفة مفاهيم ونظام الإدارة الضريبية ودراسة مراحل تطور الإدارة الضريبية للضرائب على الدخل في مصر ، ودراسة أساليب قياس الأداء الفعال للإدارة الضريبية.

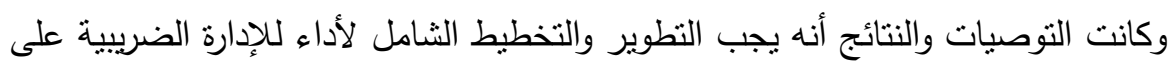
الدخل، ويجب تطوير أساليب قياس فعالية أداء الإدارة الضريبية لتعكس اهداف السياسة

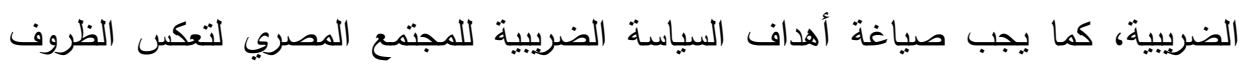
السياسية والاقتصادية والاجتماعية السائدة، كما يجب توفير الهيكل التتظيمي الملائم لطبيعة الإدارة الضريبية، ويجب نوفير الأساليب الفنية الملائكة لتحقيق وظائف الإدارة. 


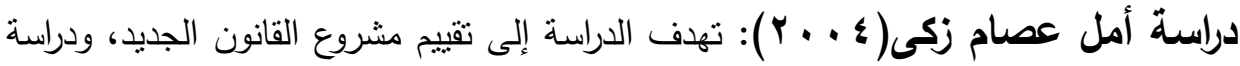

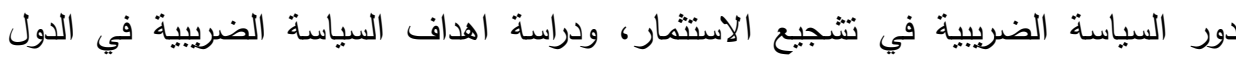

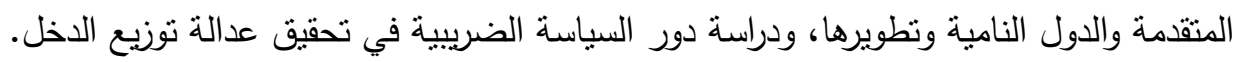

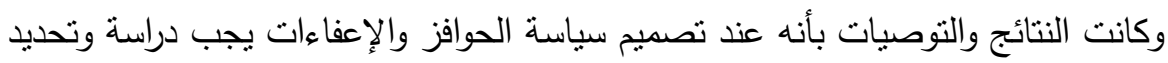

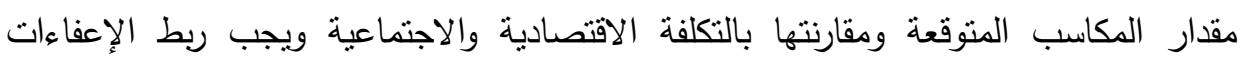

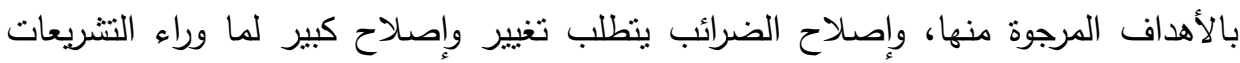
الضريبية تتمثل في العلاقة بين المصالح الضريبية وممولها، وهدف الحصيلة الضريبية هو الطياه

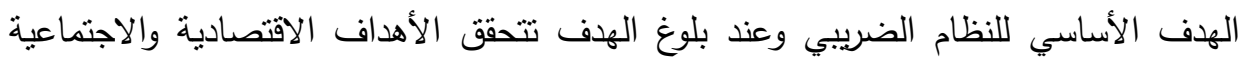
الأخرى،كما أن السياسة الضريبية المصرية تراعي البعد الاجتماعي.

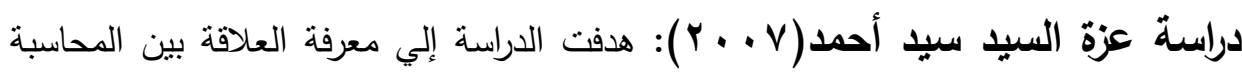

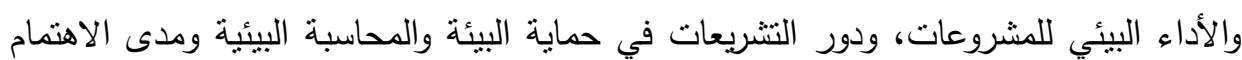

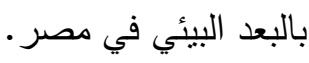

وتهدف إلى معرفة الانعكاسات المحاسبية للأنثطة البيئية، وكيفية قياس الأداء البيئي

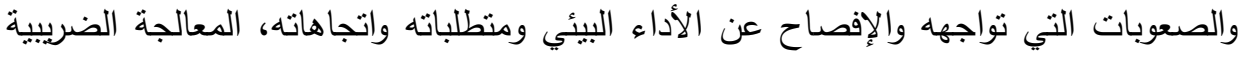

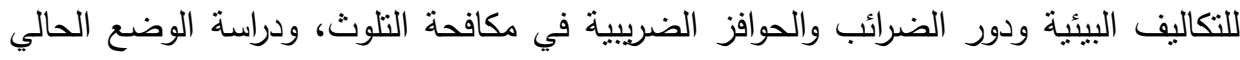
في مصر، وكيفية الدعالجة المحاسبية والضريبية للتكاليف البيئية.

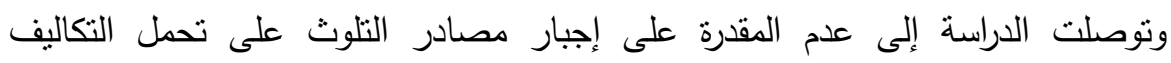

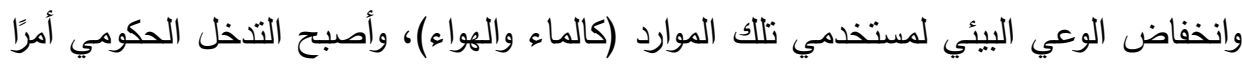

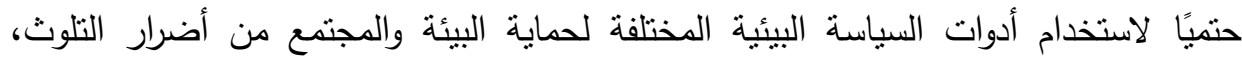

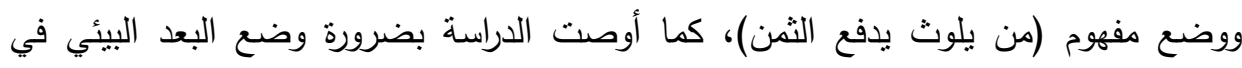
الأعنبار عند تصميم المشروعات الجديدة.

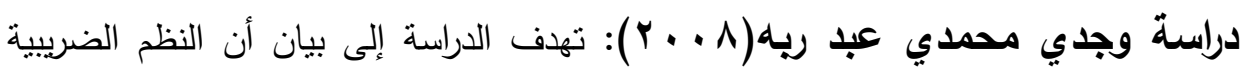

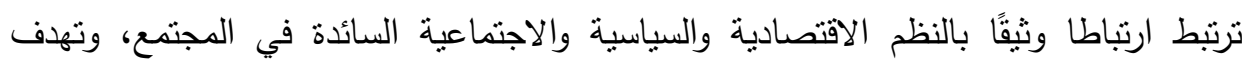

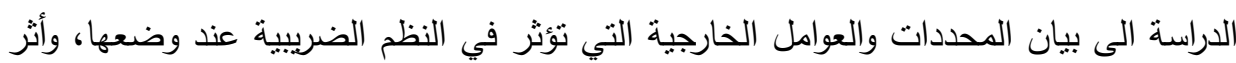

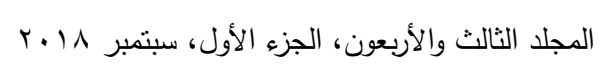




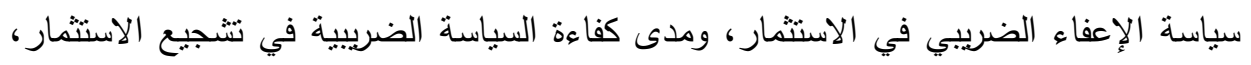

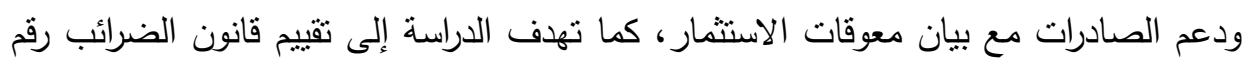
19 لسنة ه . . r وأثزه في عدالة توزيع الدخل والاستثمار وتحقيق التنمية.

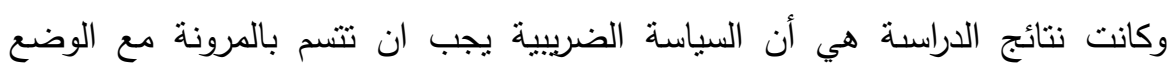

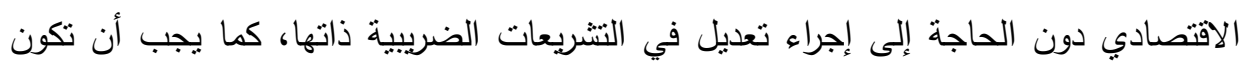
هناك تتاسق وتكامل بين أهداف السياسة الضريبية وأهداف السياسة المالية عند تصميم السياسة الضربيية. دراسة سمية قنيدرة( 9 . . ץ): هدفت الدراسة إلى تسليط الضوء على المؤسسات الصغيرة والمتوسطة والمشكلات التي تواجهها وتعوق نموها وتطورها، وإلقاء الضوء على الدور الذي الذي يمكن أن تساهم به في تحقيق التتمية المحلية بمعالجة أحد معضلاتها ألا وهي البطالة.

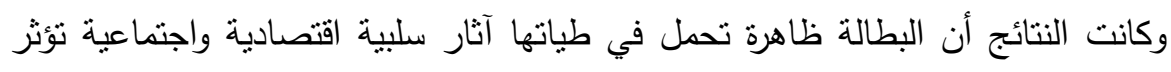

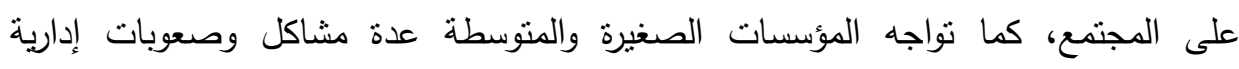
وبيروقراطية وعراقيل مالية وتنويقية، مما يعيق الثباب الحيوي في المساهمة في النشاط الاقتصادي. وأوصت الدراسة بالعمل على إزالة مختلف الحواجز الادارية والإجراءات لانشاء المؤسسات الصغيرة والمتوسطة، وتتجيع هذه المؤسسات حتى تصبح فعالة في الحد من ظاهرة الصنا البطالة. دراسة سماح مصطفى عبد الغني(Y Y Y Y): هدفت الدراسة إلى القاء الضوء على مفهوم

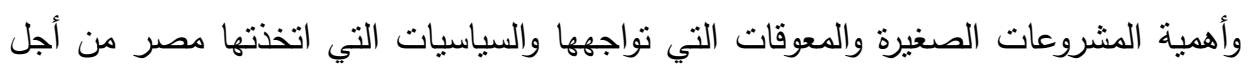
تفعيل دور المشروعات الصغيرة والمتوسطة في خدمة اهداف التتمية في مصر .

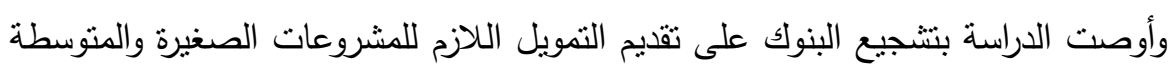
مع تطبيق نظام ضمان للقروض المقدمة لتلك المشروعات، وتوفير دليل شامل بالقوانين التي لتي تتعامل معها المشروعات الصغيرة والمتوسطة، مع العمل على تيسير إجراءات تسجيل وتشغيل

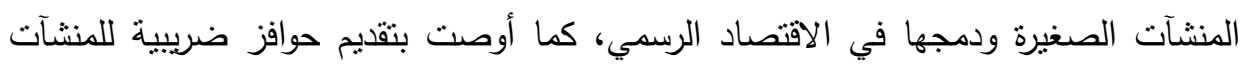
الكبيرة التي تتعاقد مع المنشآت الصغيرة او المنوسطة. 


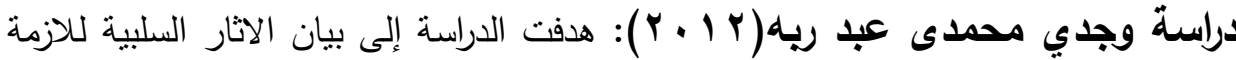

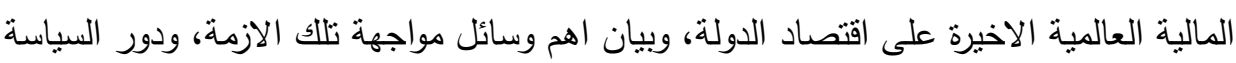

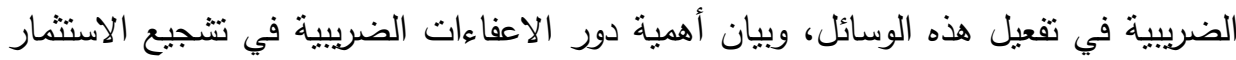
في ظل الازمات الاقتصادية، وبيان مدى مرونة السياسة الضريبية الدصرية في مواجهة الازمة الإنة

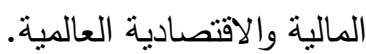
وكانت الننائج والنوصيات بأن هناك قصور في مرونة النظام الضريبي المصري على

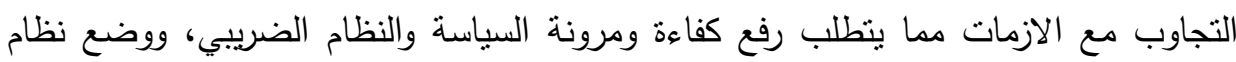

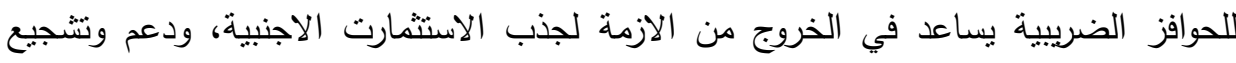

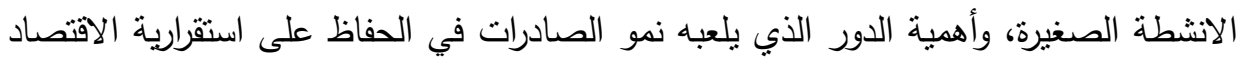
ودور النظام الضريبي في دعمه.

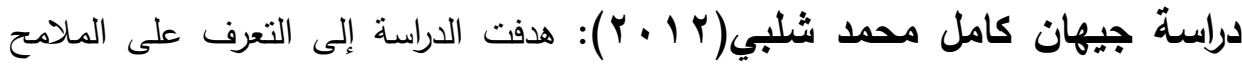

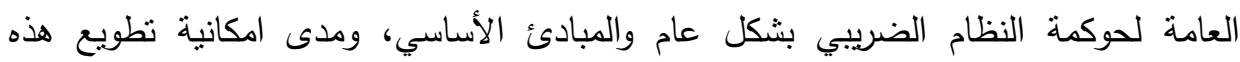
المبادئ للتطبيق على هيكل النظام الضريبي الصصري. وكانت الننائج والنوصيات بأنه يمكن تطبيق مبادئ الحوكمة على النظام الضريبي

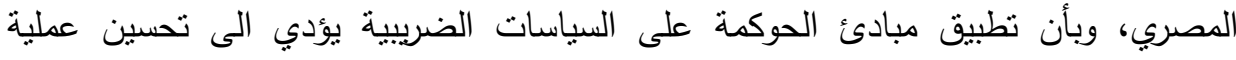

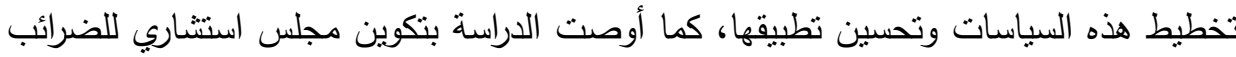

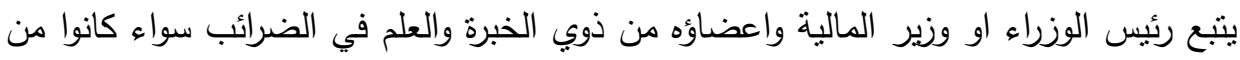

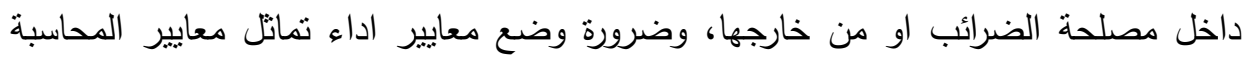

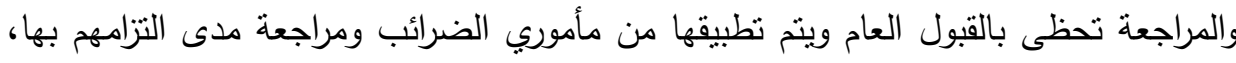

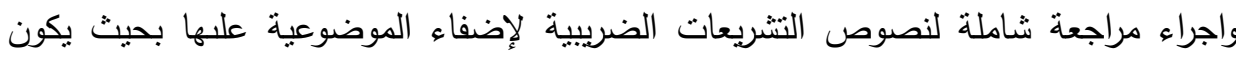

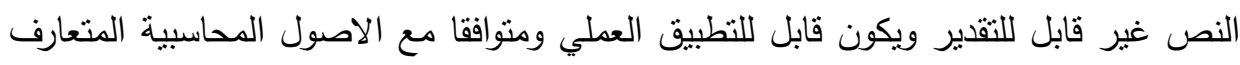
علنها. 


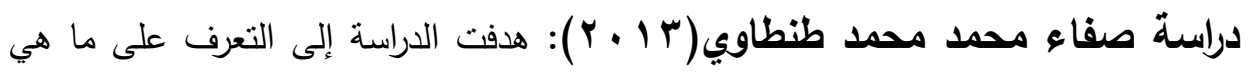

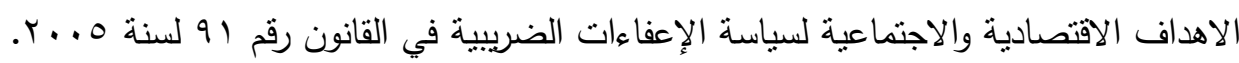

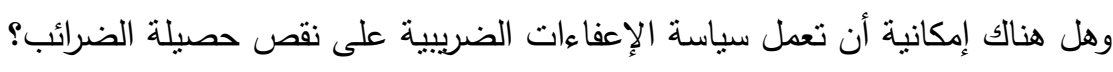

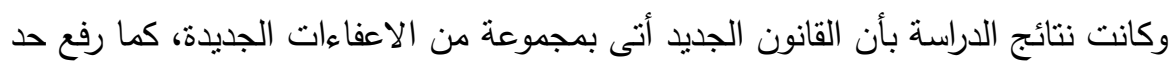

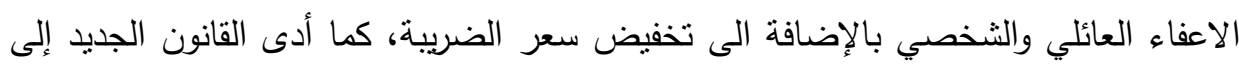

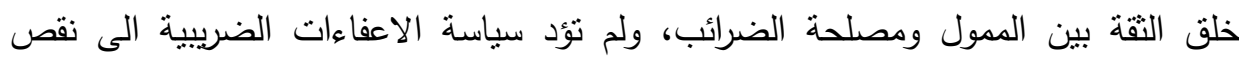

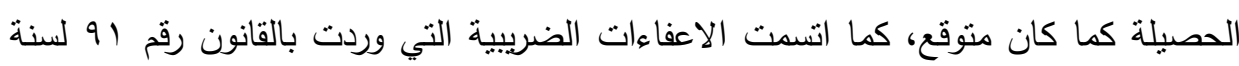

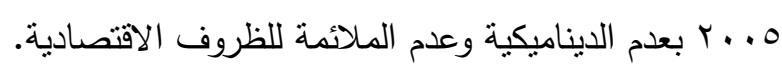

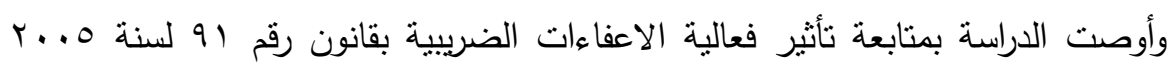

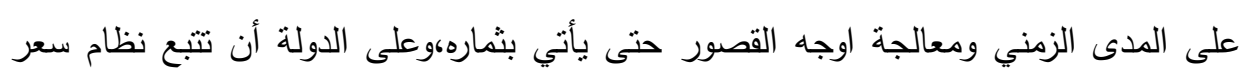

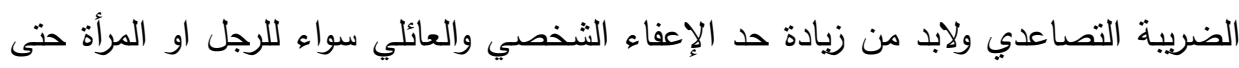

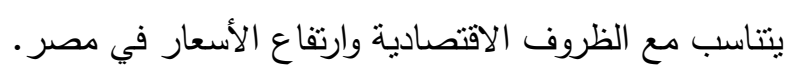

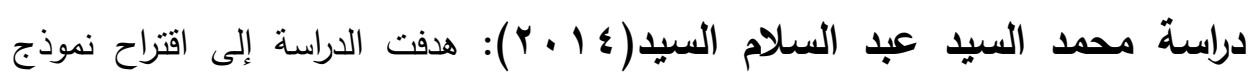

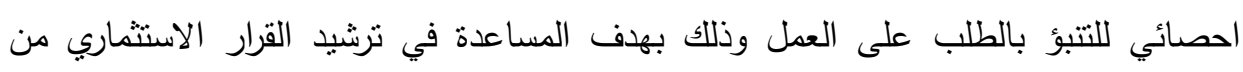

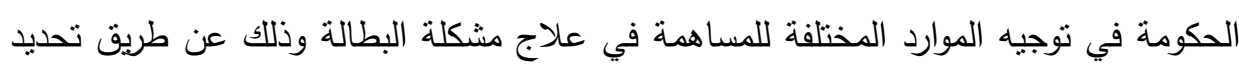

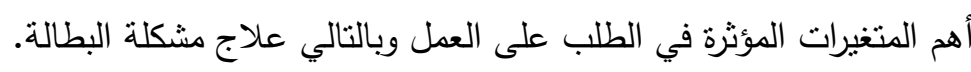

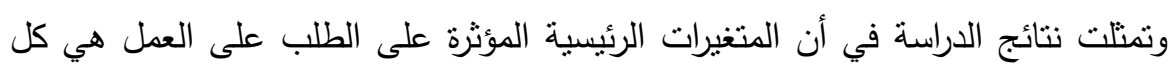

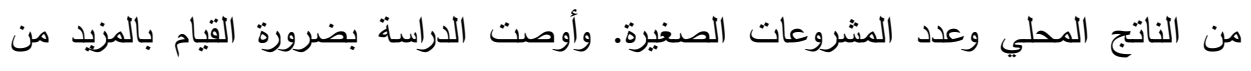

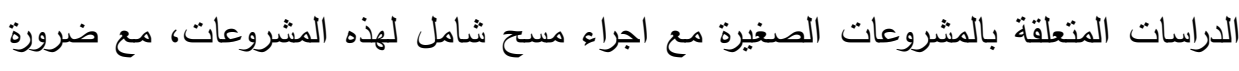

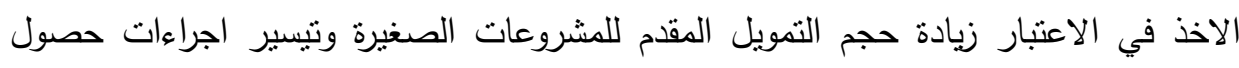

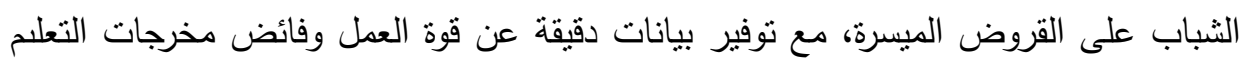

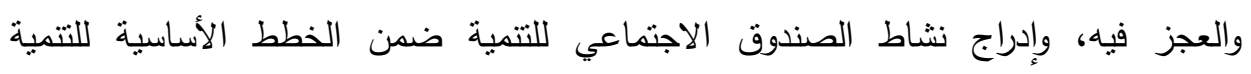

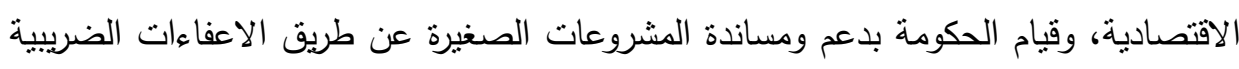

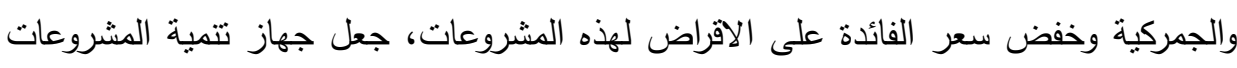
الصغيرة كيان مستقل ومنفصل داخل الصندوق الاجتماعي للتنمية. 


\section{الإلطار اللزظيه}

أولًا: التقييم البيئى للمنظومة الضريبية:

أدوات النظام الضريبى للحد من تكاليف التلوث البيئي:

الضريبة على المنتجات: تقوم الحكومة بفرض ضريبة قيمية أو نوعية على الأنتاج في مختلف

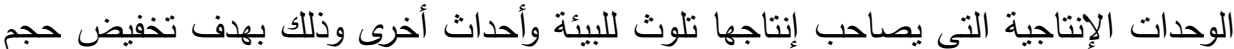

الملوثات إلي المستويات المقبوله إجتماعيًا. (David clnellor, 1995, p.108)

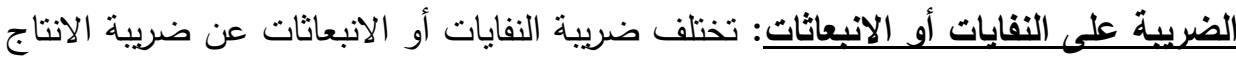
في أن هذه الضريبة تفرض على مخلفات النشاط الإنتاجى للوحدات الأقتصادية، كما أنها

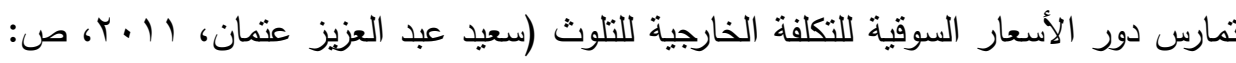

الحوافز الضريبية: تعرف الحوافز الضريبية بأنها قيام الدولة بالتضحية بجزء من مواردها لتحقيق

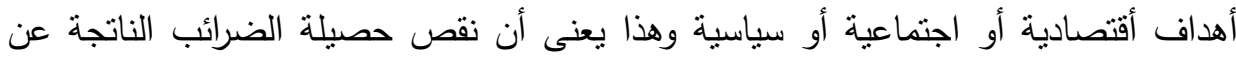
الإعفاءات الضريبية يقابله منفعة إجتماعية أو اقتصادية أو سياسية (منيرة مكرم ميخائيل،

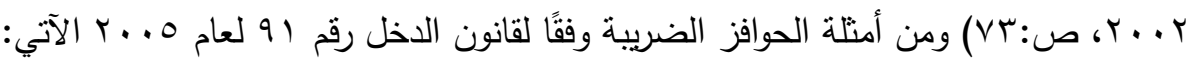
الإهلاك المعجل: يعد الإهلاك المعل طريقة تؤدى إلي إهلاك التكلفة الناريخية للأصول

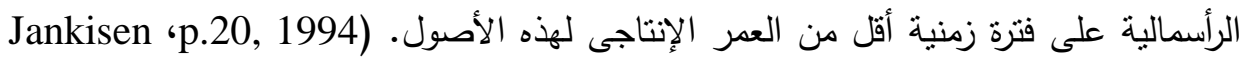

(glenn and Ranjit Lamech الإهلاك المؤجل: يقصد به نأجيل حساب الاستهلاك خلال عدد معين من السنوات إلي ما بعد

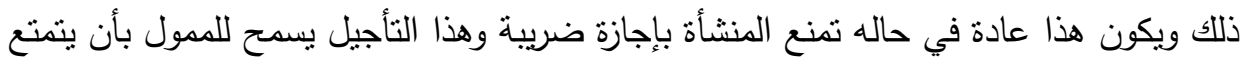

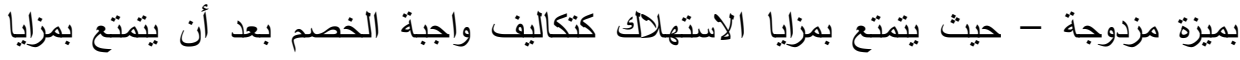

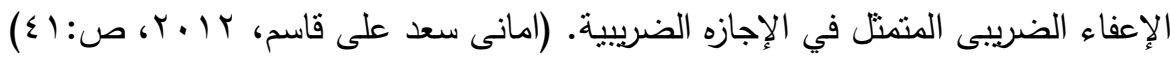

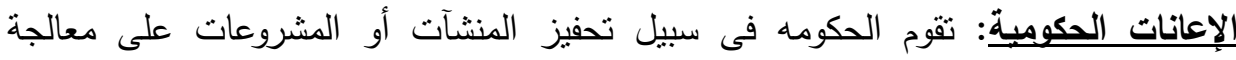

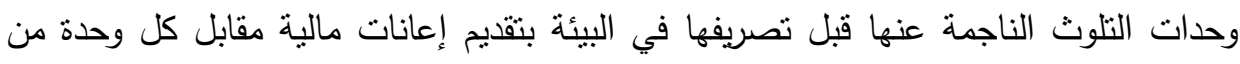
وحدات التلوث يتم معالجتها قبل التصريف اعتقادًا منها أن هذه الإعانات يمكن ان تثكل حافنات

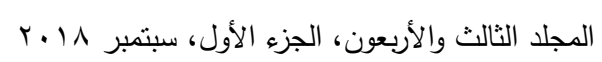


لتخفيض حجم التلوث واختيار التكنولوجيا المناسبة لذلك. (عزة السيد سيد أحمد، V.....،

ص: (YT)

تصاريح التلوث القابلة للتداول: تصاريح التلوث القابلة للتداول تقوم على أساس تحديد مسنوى

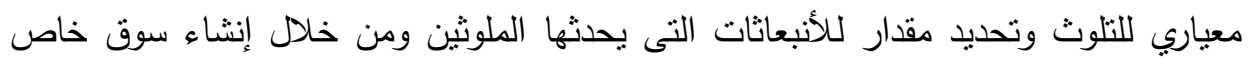

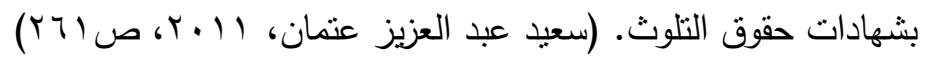

$$
\begin{aligned}
& \text { صعويات ومشاكل تطبيق نظام الضرائب على التلوث البيئى: }
\end{aligned}
$$

• صعوبة إدخال التعديلات اللازمه على النظام الضريبى القائم لمواجهة الآثار التوزيعيه

السالبه المترتبة على تطبيق الضرائب البيئية. (Yoram Bauma, 2004, p.1)

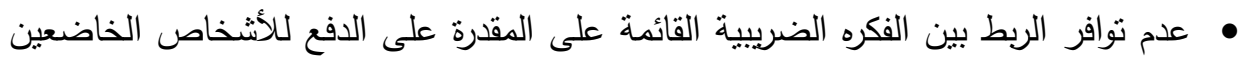

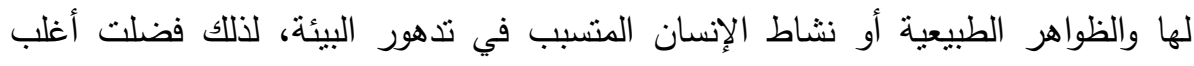
الدول اللجوء إلي حوافز ضريبية يتمتع بها من بمارس أعمالًا من شأنها الحفاظ على البيئة.

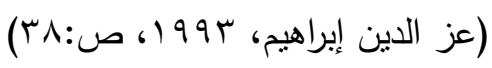

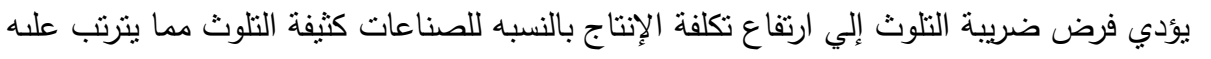

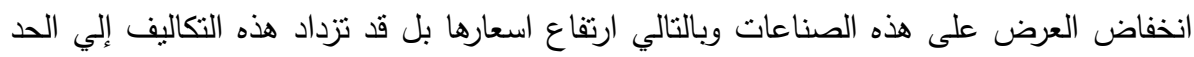
الذى يؤدى إلي خسارتها والتوقف عن النشاط مما يؤدى إلي تسريح العمال وتفاقم مشكلة البطالة وعلى عكس المشروعات قليلة التلوث تكون أكثر كفاءة في استخدام الموارد الطبيعية وأقل تأثيرًا

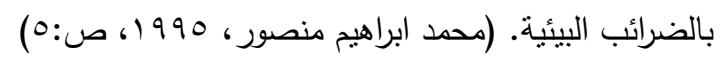$$
\text { التقييم البيئى للنظام الضريبي وأثره على البطالة في مصر : }
$$

• النظام الضريبى المصرى افتقد إلي عدم وجود الضرائب البيئية مما أدى إلي ضياعي إيطي إيرادات

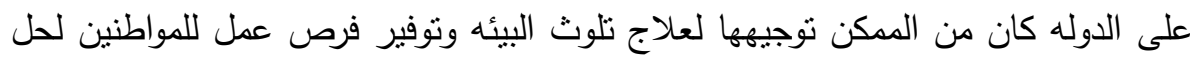
مشكله البطالة ايضًا. • عدم إدراج حمايه البيئه كهدف من أهداف النظام الضريبى المصرى لذا برى الباحثون تعديل التشريعات الضريبية بما يتوائم وحماية البيئة. وجود صعوبات في تطبيق الضريبة البيئية على المشروعات الصغيرة فيرى الباحثون بهن استخدام الحوافز الضريبية للششروعات الصغيرة واعفاءها من هذه الضريبة في بداية 
المشروع ليكن • ا أعوام على أن توفر فرص عمل للمواطنين واجبارها بإستخدام تكنولوجيا

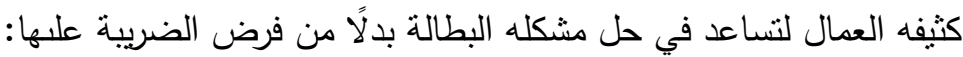
- - لتقليل مشكلة البطالة من خلال المشروعات الصغيرة كثيفة العمالة. - لتوفير تكلفه فرصه العمل الجديده التي كانت ستتحملها الدوله من توظيف العمالة وتوجيهـا إلى الحد من مشكلة التلوث وحلها في نلك المشروعات. - إعطاء فرص للمشروعات الصغيرة بأن تكبر وتتحمل ضريبة التلوث حيث أن المشروعات الصغيرة لا تسنطيع أن تتحمل ضريبة التلوث في بدايه المشروع.

تقييم النظام الضريبى من وجهه النظر الأقتصادية:

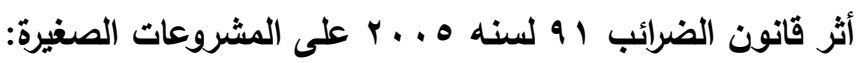
أهداف الإعفاعت الضريبية الأقتصادية: تأتى أهمية الإعفاءات الضريبية من حيث أنهات أنهات نساهم في جذب الاستثمارات الأجنبية وتتمبة الاستثمارات الوطنية وتهدف إلي زيادة حجم المدخرات الإعاء

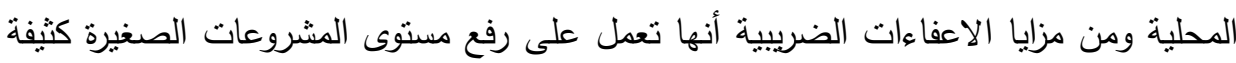

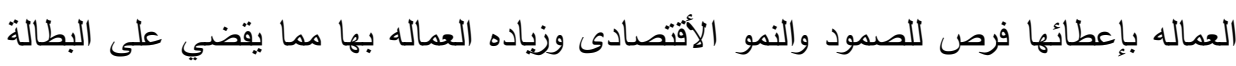

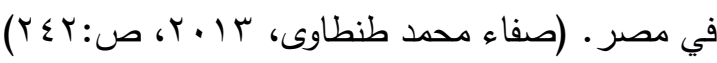

\section{هناك بعض المشكلات في محاسبة المشروعات الصغيرة منها:}

• مشكلة خضوع شركات الأثخاص للضريبة دون خصم شريحه معفاه وتحاسب بسعر ضريبى بواقع

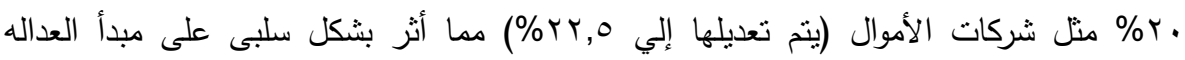

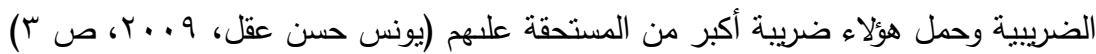
• مشكلة تضارب بعض مواد القانون مع بعضها البعض وتضاربها مع بعض مواد مواد اللائحه

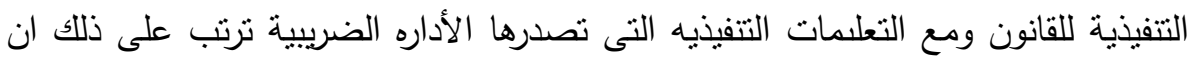
القانون لم يسنطع حل المشاكل التى نواجه الممولين والادارة الضريبية (محمد شعبان • مشكلة الأنشطة التى لا تستطيع توفير مستتدات مؤيده للتكاليف والنفقات والتى تخصم بنسبه (\%v) حيث يشتى الممولين من فلاحين ومزارعين ومربيين لا يتوافر لديهم فواتير منل 
المطاعم الثُعبيه وتجارة الخرده، تجار الاسمدة العضوية (سامى محمود عبد الحميد،

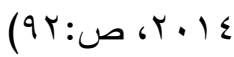

• مشكلة عدم وجود انساق في تحديد عناصر الوعاء الضريبى بين نصوص القانون ومعايير

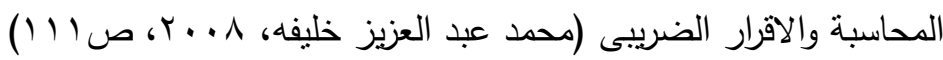

ثالثًا: المشروعات الصغيرة كحل من حلول البطالة: يرجع الإهتمام بالمشروعات

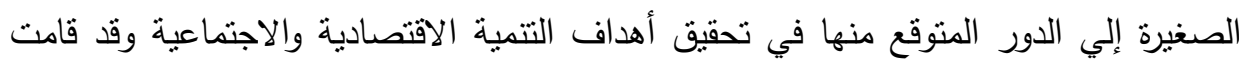

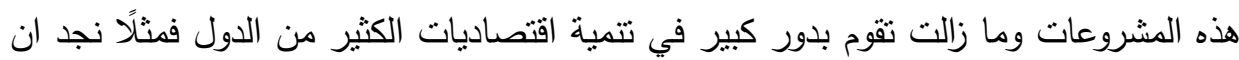
المشروعات الصغيرة لها دور كبير في دعم النهضه الصناعيه لليابان ودول جنوب شرق آسيا،

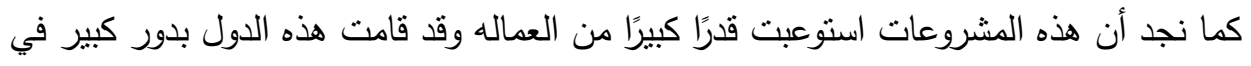

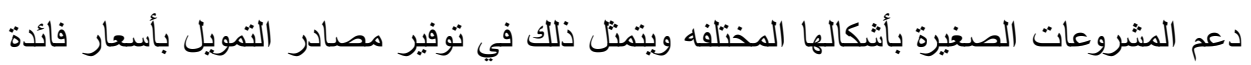

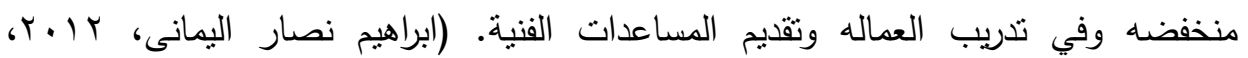
ص: (1.)

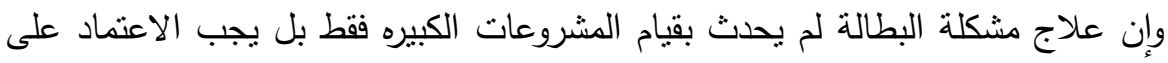

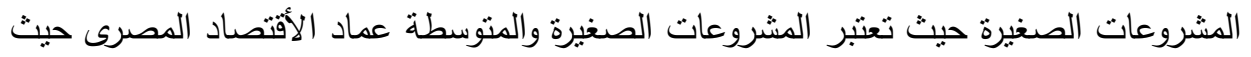

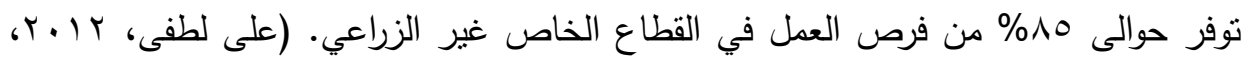

لذلك بدأت الدولة بتشجيع قيام المشروعات الصغيرة ومساندة المشروعات التى لها احتمالات تصديرية عن طريق رفع جودة السلع والخدمات للمساهمه في علاج مشكلة البطالة

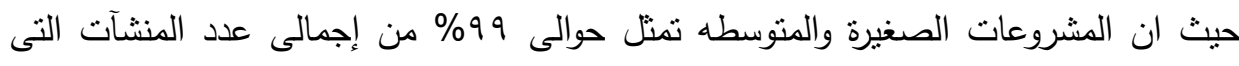
تعمل في القطاع غير الزراعى ويساهم هذا القطاع بحوالى .^^\% من لإجمالى القيمة المضافة للاخل القومى ويعمل بها حوالى بTV\% من القوي العالمه بالقطاع الخاص كحل. (محمد السيد

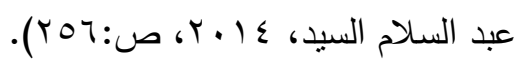

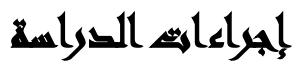

منهج البحث: اتجهت الدراسة إلى الجمع بين الدراسة النظرية والنطبيقية لذا اعتمد الباحثون على منهجين أساسيين هما: 
المنهج الاستقرائى: يهدف إلي بناء إطار لأبعاد مشكلة البحث وأهدافه من خلال الاعتماد على مأى

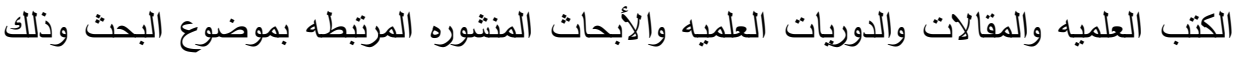
بهدف معرفه التقييم الييئى والأقتصادى للمنظومه الضريبية وأثثر على المشروعات الصغيرة كحل من حلول مشكله البطالة في مصر . المنهج الوصفي: يقوم الباحثون من خلاله بالتحليل اللوصفى للبيانات المستخرجه من سجلات

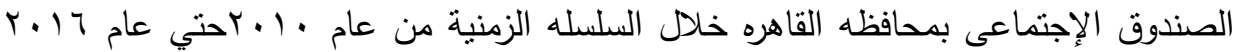
الخاصه بالمشروعات الصغيرة والمتناهيه الصغر المموله تمويل مباشر من وجهات وسيطة او المشروعات المموله من جمعيات أهلية وبنوك وتتشكيل رسم بيانى ووصف النتائج المقترحة وتم قياس قوة العلاقة بين المتغيرات بإستخدام معامل الارتباط لبيرسون.

\section{مشوض الفواسم}

الحدود المكاتية: اعتمد الباحثون على بيانات الصندوق الاجتماعي بمحافظة القاهرة نظرًا لأنها أكبر محافظات الجمهوريه من حيث عدد السكان وبالتالي فمحافظة القاهرة يمكن اعنبارها

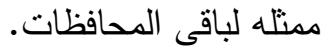
الحدود الزمنية: اعتمد الباحثون على بيانات السلسله الزمنية من عام • ـ ـ إلى عام 17 ـ ؟.

\section{هروخ التواسم}

الفرض الأول: توجد علاقة ذات دلالة معنوية بين التقييم البيئي للمنظومة الضريبية والبطالة. وينبنق منه الفروض الفرعية التالية: • توجد علاقة ذات دلاله معنوية بين عدد المشروعات الصغيرة المموله من جهات وسيطة ومباشرة ونسبة البطالة للذكور . • توجد علاقة ذات دلاله معنوية بين عدد المشروعات الصغيرة المموله من جهات وسيطة ومباشرة ونسبة البطالة للاناث. • نوجد علاقة ذات دلاله معنوية بين عدد المشروعات متتاهية الصغر والممولة من جمعيات أهليه وبنوك ونسبة البطالة للذكور • 
• توجد علاقة ذات دلاله معنوية بين عدد المشروعات متتاهية الصغر والممولة من جمعيات أهليه وبنوك ونسبة البطالة للاناث.

الفرض الثاني: توجد علاقة ذات دلالة معنوية بين التقييم الاقتصادي للمنظومة الضريبية

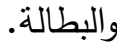

\section{أواله الهميش}

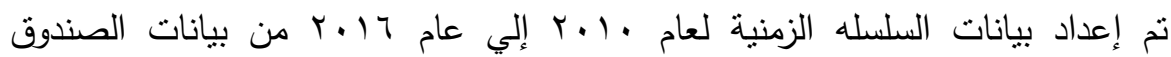
الاجتماعي بمحافظة القاهرة واعتمدت هذه الدراسة على ثلاثة محاور كالتالي: المحور الاول: التقييم البيئى للمنظومه الضريبية: تم التعبير عن هذا المحور باستخدام مصادر التمويل، حيث ان هناك مصدرين لتمويل المشروعات، هما التمويل عن طريق جهات وسيطة ومباشرة والتمويل عن طريق جمعيات أهليه وبنوك. حيث تم الاعتماد على عدد المشروعات الصغيرة والممولة من جهات وسبطة ومباشرة للذكور وعدد المشروعات الصغيرة والممولة من جهات وسيطة ومباشرة للاناث. وكذلك عدد المشروعات متتاهية الصغر والممولة من جهات وسيطة ومباشرة للذكور وعدد المشروعات متتاهية الصغر والممولة من جهات وسيطة ومباشرة للاناث. وبهذا اعتمد البحث على اربعة متغيرات للتعبير عن المحور الاول

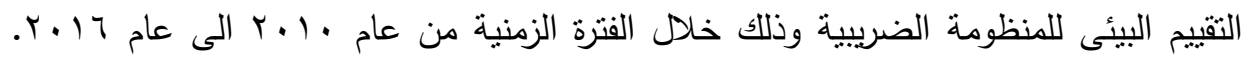
الجدول التالي يعرض المتغيرات المستخدمه للتعبير عن المحور الاول فى الدراسة. جلول( (1): متغيرات الدراسة الخاصة بالتقييم البيئي للمنظومة الضريبية

\begin{tabular}{|c|c|c|c|c|}
\hline ألصغرعات متئاهية & مشروعات متناهية & مشروعات صنيطة & مشات وسبطة & السنة \\
\hline$r 1.0$ & 977 & 91 & $\varepsilon 1 \pi$ & $r .1$. \\
\hline $\begin{array}{l}T T \\
\end{array}$ & $\Lambda .0$ & $1 \leqslant \Lambda$ & 07. & 5.11 \\
\hline rAT & $\varepsilon r \mu$ & $1 \wedge 1$ & 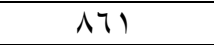 & $r . I T$ \\
\hline ror & $1 \leqslant 9$ & $19 \varepsilon$ & $9 \leqslant Y$ & $r .1 T$ \\
\hline $71 \pi$ & $v \leqslant 9$ & YOV & 1849 & $r .1 \varepsilon$ \\
\hline$\varepsilon \wedge 9$ & rAl & ro1 & 1,74 & $r .10$ \\
\hline 94. & OTr & 119 & $1 . \leqslant 7$ & 5.17 \\
\hline
\end{tabular}


المحور الثانى: التقييم الاقتصادى للمنظومة الضريبية: لقد اعتمد الباحثون على نسبة

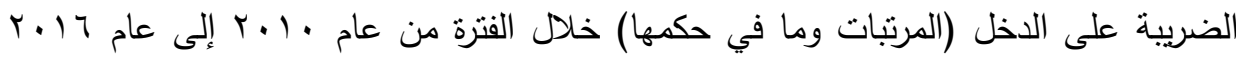
طبقًا للجدول التالي. جلول(ץ): نسبة الضريبة على الدخل (المرتبات وما فى حكمها) في محافظة القاهرة

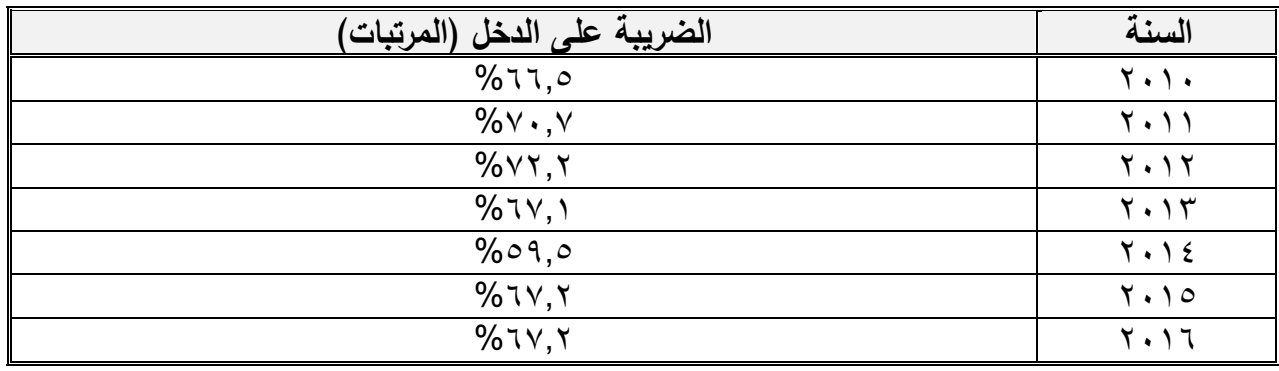

المحور الثالث: البطالة: لقد اعتمد الباحثون على نسبة البطالة للأكور ونسبه البطالة للأناث

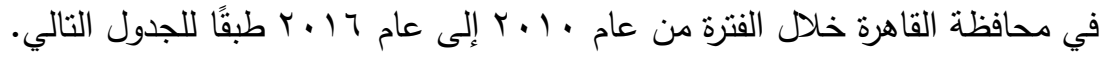
جدول(ץ): نسبة البطالة للذكور والإناث في محافظة القاهرة

\begin{tabular}{|c|c|c|}
\hline نسبة البطالة القاهرة إناث & نسبة البطالة القاهرة ذكور & السنة \\
\hline$\%$ \% & \%rr, & T.1. \\
\hline$\% \leqslant \vee, r$ & $\%$ \%०, 1 & $r .11$ \\
\hline$\% \circ r$ & \%rr,T & $T . M T$ \\
\hline$\% \leqslant \vee, 1$ & $\%$ \% $1, q$ & $r .1 T$ \\
\hline$\% \leqslant \vee, q$ & $\% \backslash 9,1$ & T.I \\
\hline$\% \leqslant \vee, 1$ & $\% \curlyvee q, 7$ & $T .10$ \\
\hline$\%$ \% १, ₹ & \%rr,V & $T .17$ \\
\hline
\end{tabular}

العينة: نم نطبيق هذه الدراسة على المشروعات الصغيرة والمتتاهية الصغر المموله من جهات وسيطة ومباشرة والممولة من جمعيات أهلية وبنوك وتم تقسيمها إلى إناث وذكور بالصندوق الاجتماعي للتنمية بمحافظة القاهرة.

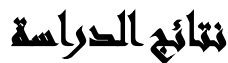

لاختبار الفرض الأول قام الباحثّن باستخدام تحليل الأرتباط لبرسون لقياس قوة واتجاه

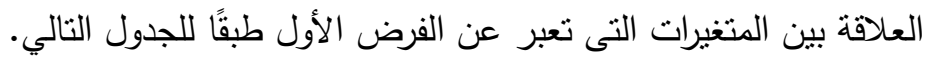


جدول(§): معاملات الارتباط بين كل زوج من ازواج متغيرات الفرض الاول واختبار الجوهري لكل معامل ارتباط

\begin{tabular}{|c|c|c|c|c|c|c|c|}
\hline 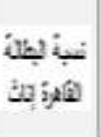 & & 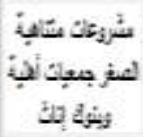 & 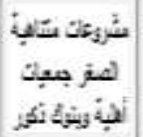 & 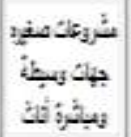 & 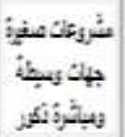 & & \\
\hline,,$+ \ldots-$ & 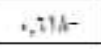 & $0.0+4-$ & $\cdot, t, t-$ &., 904 & 1 & 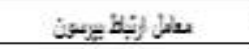 & \multirow{2}{*}{ 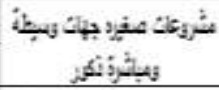 } \\
\hline$\therefore, \ldots 2$ & $1,+$, &.,$\pi t$ & $+\pi$ & $\cdot, \cdot, 1$ & & 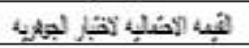 & \\
\hline,$++t)-$ &,, 111 & $, y: 4-$ & $4,024-$ & 1 & , tar & سطل ربلا بيرسئ & \multirow{2}{*}{ شرز } \\
\hline 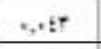 & , Att & , &, $14 t$ & & $,, \cdot, 1$ & 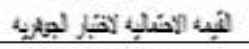 & \\
\hline 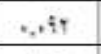 & , $214-$ &,$y !=$ & 1 & , $284-$ & $x, 8+1-$ & 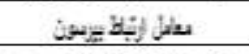 & \multirow{2}{*}{ 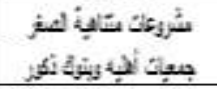 } \\
\hline - At:2 & $+\ldots$ &,$++4 !$ & &., $14 t$ & 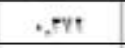 & 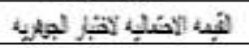 & \\
\hline , vitr- & $.1 \pi-$ & 1 & $+, Y: 2$ & $c, y \pm 4-$ & , $254-$ & 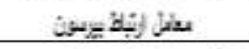 & \multirow{2}{*}{ 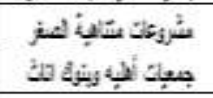 } \\
\hline$\therefore,+.4$ &,$y 42$ & &,++41 & $\cdot,+2 r$ & $t, \pi t$ & 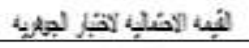 & \\
\hline 5,$1 ; 2-$ & 1 & , &,,$y 14-$ &., 111 & $4,51,4-$ & 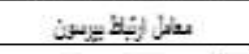 & \multirow{2}{*}{ 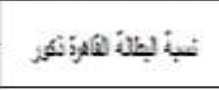 } \\
\hline$*, r t:$ & & $8, y+2$ & $t, \ldots+$ &,$+ A+t$ &,,+ 11 & 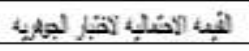 & \\
\hline 1 &., 178 & $=, y 1 \%-$ & 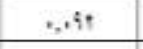 & $+\pi i t$ & $, \mathrm{i}, \ldots-$ & 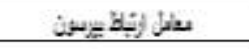 & \multirow{2}{*}{ - } \\
\hline & , YTt: &,$\ldots 9$ & At: &,$++t^{\prime}$ & $\ldots, \cdots$ & 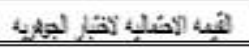 & \\
\hline
\end{tabular}

من هذا الجدول يتضح أن هناك علاقة جوهرية سالبة بين عدد المشروعات الصغيرة المموله من جهات وسيطة ومباشرة للذكور عدد المشروعات الصغيرة المموله من جهات وسيطة

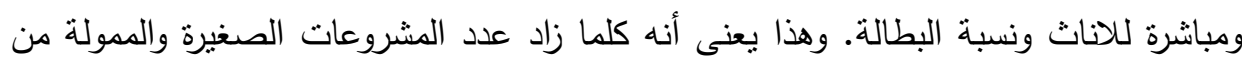
جهات وسيطة ومباشرة انخفضت نسبة البطالة للذكور والاناث. كما يلاحظ وجود علاقة جوهرية سالبه بين عدد المشروعات المتتاهية الصغر والممولة من جمعيات اهليه وبنوك للاناث وهذا يعنى انه كلما زاد عدد المشروعات المتتاهية الصغر والممولة من جمعيات اهليه وبنوك لهن والمخصصه للاناث ادى ذلك الى انخفاض معدلات البطالة للاناث. 
ولاختبار الفروض الفرعية للفرض الأول، الجدول التالي يعرض نتائج اختبار الفروض الفرعيه المنبقة من الفرض الرئيسي الأول.

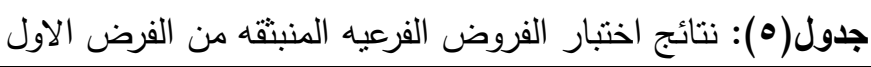

\begin{tabular}{|c|c|c|c|c|c|}
\hline القرار & الاحتماليه & الارتباط & الثتانغير & المتغير الاول & رقم الفرض \\
\hline الفرض & ., & . & نسبة البطالة & عدد المشروعات الصغيرة المموله & 1 \\
\hline الفرض & $\cdot, \cdot \varepsilon$ & «1 & نسبة البطالة & عدد الشرات وسبطة ومغياتشرة الموله & r \\
\hline الفرض & $\cdot, \ldots r$ & - . & نسبة البطالة & والمدولة من جمعيات الهليه وبنوك المغر & r \\
\hline الفرض & $\cdot, \ldots q$ & $\cdot, v \backslash r-$ & نسبة البطالة & والمدولة من جمعيات اهلكيه وبنوك المنت & $\varepsilon$ \\
\hline
\end{tabular}

من هذا الجدول توافر لاى الباحثنون اثبات قوى بمعامل ثقه 90\% وبنه انه توجد علاقة جوهرية سالبه بين عدد المشروعات سواء كانت مموله من جهات وسيطة ومباشرة أو مموله من جمعيات اهليه وبنوك ونسبه البطالة في محافظه القاهره للأكور والأناث وبالتالى قبول الفرض العند العدم الأول والقائل: "توجد علاقة ذات دلالة معنوية بين التقييم البيئي للمنظومة الضريبية والبطالة باحتمال ثقه قدره 90\%". اختبار الفرض الثانى: الجدول التالي يوضح نتائج معاملات الارتباط بين كل زوج من ازواج متغيرات الفرض الثانى واختبار الجوهرى لكل معامل ارتباط.

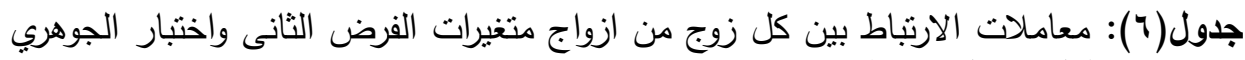
لكل معامل ارتباط الإنياط

\begin{tabular}{|c|c|c|c|c|}
\hline & & القاذبة البطالة & القانهة البطاثة & الضريبة في على الاخل \\
\hline \multirow{2}{*}{ القاذهره ذالبطور } & معامل ارتباط بيرسون & 1 & $-v 70 .$. & $-\Lambda Y \varepsilon . \cdot$ \\
\hline & لاختبار الجوهرية الاحتية & & . & $\cdot, \cdots \varepsilon$ \\
\hline \multirow{2}{*}{ القاذبة البطالة اناث } & معامل ارتباط بيرسون & $-v 70 .$. & 1 & . АVฯ- \\
\hline & لاختبار الاحتمالية & . & & $\cdot, \cdots \varepsilon$ \\
\hline \multirow{2}{*}{ الضخل وماية على } & معامل ارتباط بيرسون & -ᄉYE.. & . AVฯ- & 1 \\
\hline & لاختبار الجوهرية الاحتيه & $\cdot, \cdots \varepsilon$ & $\cdot, \cdots \varepsilon$ & \\
\hline
\end{tabular}


من هذا الجدول يتضح وجود علاقة جوهرية سالبة بين نسبة البطالة للذكور والضريبة على على الدخل، كذلك توجد علاقة جوهرية سالبة بين نسبة البطالة للإناث والضريبة على الدخل. وهذا

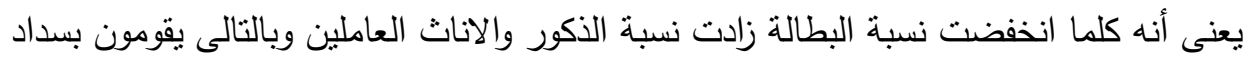
ضريبة الدخل ولقد نوافر دليل قوى لاى الباحث انه نوجد علاقة جوهرية بين نسبة البطالة

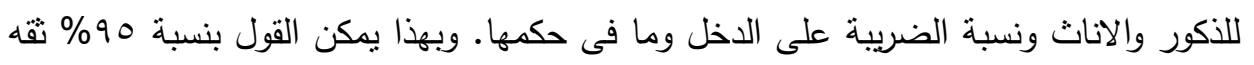
بقبول الفرض الثانى والقائل بأن: "توجد علاقة ذات دلاله معنويه بين التقييم الاقتصادى ولانيه للمنظومه الضربيية والبطالة".

\section{المتوصيامت}

ا • يوصي الباحثون بدراسة البطالة وتحديد حجمها واسبابها ونتائجها نظرًا لازدياد أعداد البطالة

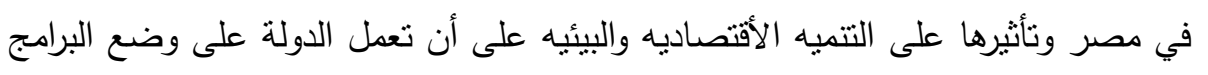
والحلول لخفض نسبه البطالة

r. يوصي الباحثون بدراسة المنظومه الضريبية في مصر من الناحيه الاقتصادية والبيئية وتقييمها وعلاج التشوهات في كل منها حيث أنه كلما قلت التشوهات في المنظومه الضريبية زادت معها الحصيله الضريبية ودارت عجلة الاقتصاد والعكس صحيح.

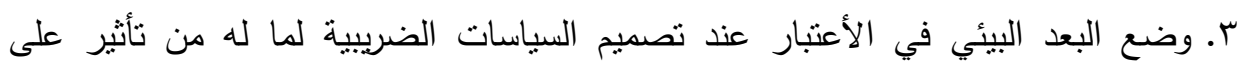

$$
\text { إيرادات الدولة. }
$$

ء. عند وضع السياسات الضريبية يتعين ربط هذه السياسات بأعداد البطالة في المجتمع حتى التى يكون هناك اتساق بين السياسات الضريبية والأهداف الأقتصاديه في المجنمع.

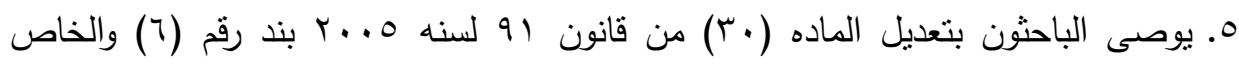
بإعفاء المشروعات الصغيرة المموله من الصندوق الجنماعي وجعلها اعفاء المشروعات الصغيرة بصفة عامة موارد ممولة من الصندوق الاجتماعى أو أي جهة أخرى وزيادة

$$
\text { هعدلات الاعفاء من (0) سنوات إلى (• (1) سنوات. }
$$

T. يوصي الباحثون بحل المشكلات الضريبية المرتبطه بمحاسبة المشروعات الصغيرة. V. دراسة تأثير تشجيع المشروعات الصغيرة وتمويلها على البطالة كأحد حلول تقييم المنظومة

$$
\text { الضريبية في مصر • }
$$

$$
\text { المجلد الثالث والأربعون، الجزء الأول، سبتمبر 11 ا.ب }
$$


^. جعل جهاز تتمية المشروعات الصغيرة كيان مستقل يتبع رئاسة الجمهورية في الاشراف عليه حتى يكون هناك فاعله وسرعه فى اصدار القرارات مما يعمل على تتمية هذه المشروعات مما يؤثر على أعداد البطالة بالتبعية.

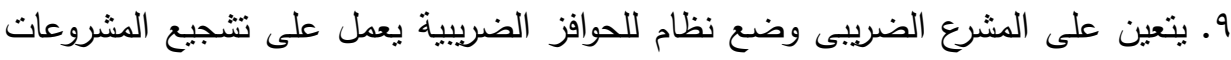
الصغيرة والمتوسطه لخفض نسبه البطالة في مصر .

\section{المرالئ}

إبراهيم نصار اليماني(Y ( • Y): محاضرات في الاقتصاد التطبيقي، بدون ناشر.

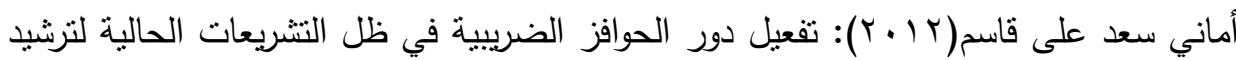
تكاليف النلوث البيئي في الدول النامية. رسالة دكتوراه، معهد الدراسات والبحوث

$$
\text { البيئية، جامعة عين شمس. }
$$

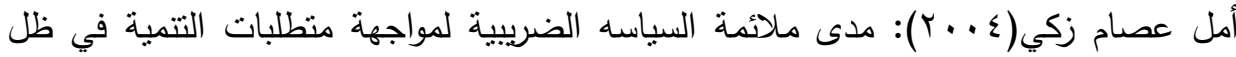
المتغيرات العالمية المعاصرة - دراسة مقارنة بالئة بين مصر - نركيا - إسرائيل،

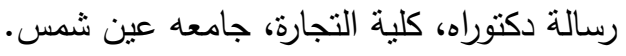

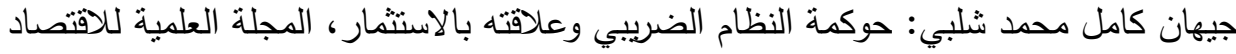

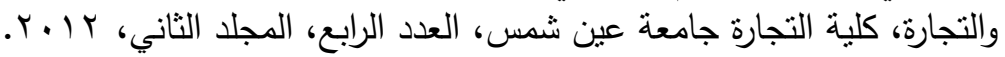

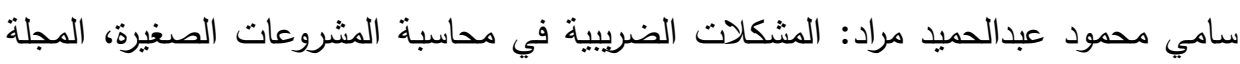

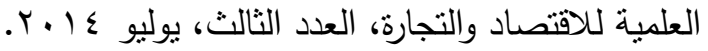

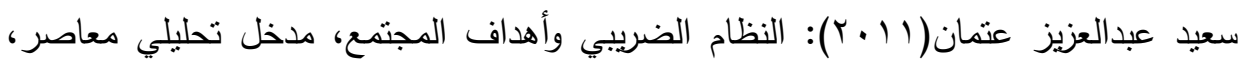

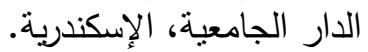

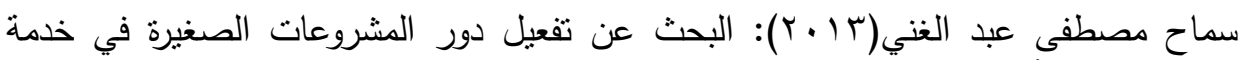
أهداف التتهية الاقتصادية المصرية، وزارة المالية.

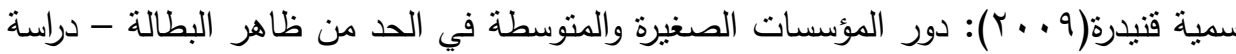
ميدانية بولاية قسطنطينة، رسالة ماجستير جامعة قسطنطين، الجزائر .

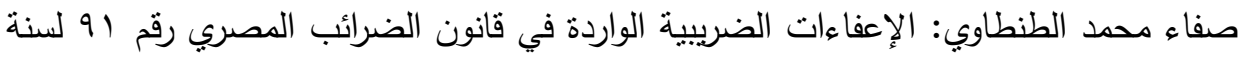

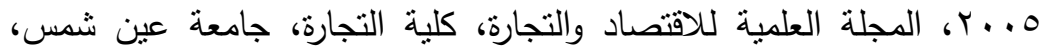

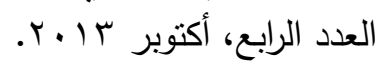

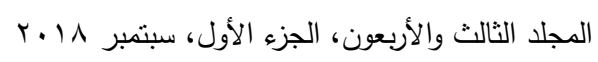


عز الدين إبراهيم: الضريبة على الكربون وحماية البيئة، مجلة العلوم القانونية والاقتصادية، كلية

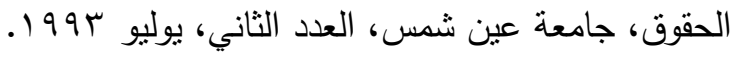

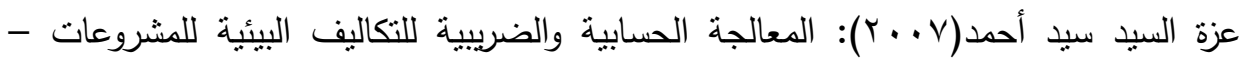

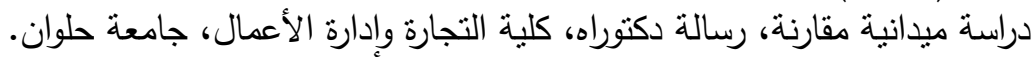

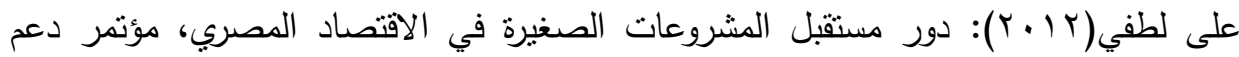
وتتمية المشروعات الصغيرة، جامعة عين شمس، كلية التية التجارة.

محمد إبراهيم منصور (99 (19): دور الضريبة في مكافحة التلوث وحماية البيئة - تحليل الآثار

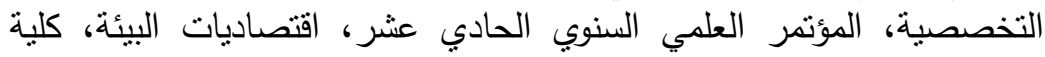

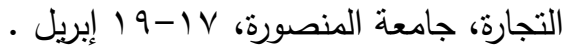

محمد السيد عبد السلام السيد: دور المشروعات الصغيرة في زيادة الطلب على العمل للمساهمة

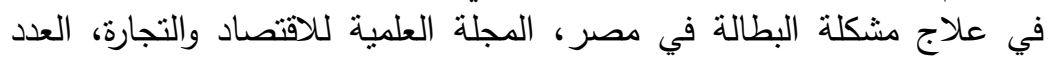

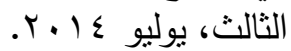

محمد شعبان الششتاوي وآخرون(1) (1 + ب): مجموعة من المقترحات المقدمة لرئاسة الوزراء ووزير

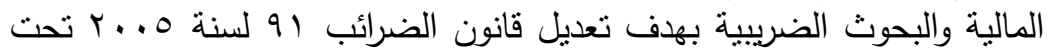

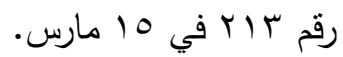

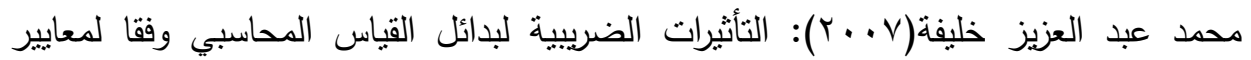

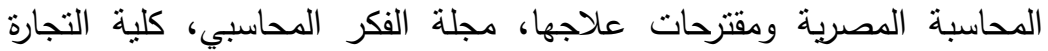

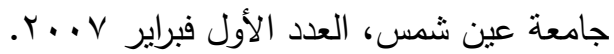

محمد عصدت درويش غانم(1991): مدى فاعلية الإدارة الضريبية في تحقيق السياسية

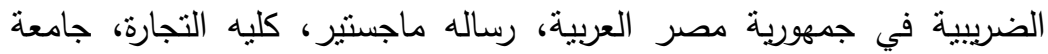
طنطا.

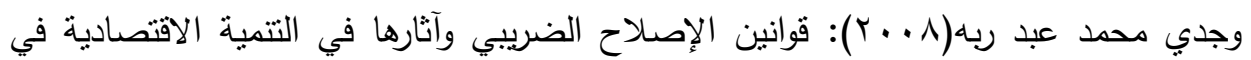
مصر ، رسالة ماجسنير ، كلية التجارة، جامعة الإح عين شمس.

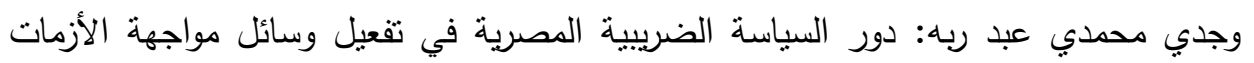

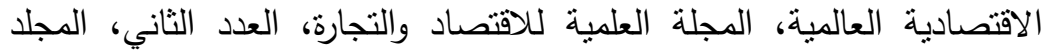

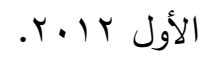

منيرة مكرم ميخائيل(r · . ب): دور الإعفاءات الضريبية وأبعادها الاقتصادية والاجتماعية والبيئية

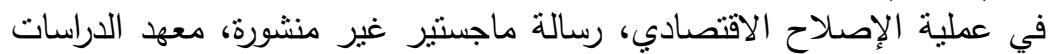
والبحوث البيئية، جامعة عين شمس. 


$$
\text { معهد الدراسات والبحوث البيئية - جامعة عين شمس البيئة }
$$

David Clnellor (1995): Environmental Taxes.

Jankinsen, Glenn and Ranjit, Lamech (1994): Green taxes and incentive policies - An international prespective. Harverd Institute for International Development, Sanfrancisco, USA.

Yoram Bauma (2004): Free Market Incentives for Innovation - Acloser Lookat the cash of Pollution Control, Whitmam College, Juney.

\title{
ENVIRONMENTAL ASSESSMENT AND ECONOMIC STATUS OF THE TAX SYSTEM AND ITS IMPACT ON UNEMPLOYMENT IN EGYPT
}

\author{
Sayed Y. M. ${ }^{(1)}$; Lotfy, M. A. ${ }^{(2)}$ and Abdel Baset, W. F. ${ }^{(2)}$ \\ 1) Taxes Authority 2) Faculty of Commerce, Ain Shams University
}

\begin{abstract}
The research aims at studying the unemployment and the reasons leading to its emergence in Egypt and its impact on the environment, society and economy. Unemployment is considered a disorder in the environmental system. The research aims to evaluate the tax system in economic and environmental terms by evaluating the Law No. 91 of 2005 and treating distortions to increase the resources of the state. The researchers used the theoretical method in the theoretical framework for research and the descriptive approach in analyzing the data extracted from the records of the Social Fund for Development in Cairo Governorate. The sample of the study On the small and micro projects during the time series from 2010 to 2016 . The study was applied to Cairo Governorate, where it represents the largest governorates of the Republic. The study was based on clarifying the extent of correlation between the environmental and economic evaluation of the tax system and unemployment.
\end{abstract}

$$
\text { المجلد الثالث والأربعون، الجزء الأول، سبتمبر 11 ب r }
$$


The researchers reached several results, including: There is a strong and inverse relationship between the economic assessment of the tax system and unemployment. There is a strong relationship between the environmental assessment of the tax system and the unemployment rate. There is an inverse correlation between the number of small enterprises financed by intermediaries and the unemployment rate. There are distortions in some articles of Law 91 of the year 2005 has an impact on the tax revenue and small projects together must be treated. Researchers recommended to study the tax system from the economic and environmental point of view, evaluate and treat distortions as it relates to state revenues and economic development. They also recommend solving tax problems associated with accounting for small businesses. The researchers recommend studying the impact of encouraging small projects and financing them on unemployment as one of the solutions to evaluate the tax system in Egypt. 